INFLAMMATORY BOWEL DISEASE

\title{
Calprotectin is a stronger predictive marker of relapse in ulcerative colitis than in Crohn's disease
}

\author{
F Costa, M G Mumolo, L Ceccarelli, M Bellini, M R Romano, C Sterpi, A Ricchiuti, S Marchi, M Bottai
}

Gut 2005;54:364-368. doi: 10.1136/gut.2004.043406

See end of article for authors' affiliations

Correspondence to:

Dr F Costa, Dipartimento di Medicina Interna-SO di Gastroenterologia,

Universita' di Pisa,

Ospedale S Chiara, Via

Roma, 67-56122 PISA,

Italy;

fcosta@int.med.unipi.it

Revised version received 3 May 2004

Accepted for publication

25 May 2004

\begin{abstract}
Background and aims: The clinical course of inflammatory bowel disease is characterised by a succession of relapses and remissions. The aim of our study was to assess whether the predictive value of faecal calprotectin-a non-invasive marker of intestinal inflammation-for clinical relapse is different in ulcerative colitis (UC) and Crohn's disease (CD).

Methods: Seventy nine consecutive patients with a diagnosis of clinically quiescent inflammatory bowel disease (38 CD and $41 \mathrm{UC}$ ) were followed for 12 months, undergoing regular clinical evaluations and blood tests. A single stool sample was collected at the beginning of the study from each patient and the calprotectin concentration was assessed by a commercially available enzyme linked immunoassay.

Results: In CD, median calprotectin values were $220.1 \mu \mathrm{g} / \mathrm{g}$ (95\% confidence interval (Cl) 21.7-418.5) in those patients who relapsed during follow up, and $220.5 \mu \mathrm{g} / \mathrm{g}(95 \% \mathrm{Cl} 53-388)$ in non-relapsing patients $(\mathrm{p}=0.395)$. In UC, median calprotectin values were $220.6 \mu \mathrm{g} / \mathrm{g}(95 \% \mathrm{Cl} 86-355.2)$ and $67 \mu \mathrm{g} / \mathrm{g}(95 \%$ Cl 15-119) in relapsing and non-relapsing patients, respectively $(p<0.0001)$. The multivariate Cox (proportional hazard) regression model, after adjustment for possible confounding variables, showed a twofold and 14-fold increase in the relapse risk, respectively, in those patients with CD and UC in clinical remission who had a faecal calprotectin concentration higher than $150 \mu \mathrm{g} / \mathrm{g}$.

Conclusions: Faecal calprotectin proved to be an even stronger predictor of clinical relapse in UC than in $C D$, which makes the test a promising non-invasive tool for monitoring and optimising therapy.
\end{abstract}

l nflammatory bowel diseases (IBD) are chronic intestinal disorders of unknown aetiology and with a typically relapsing course. The main goal of treatment in IBD is effective and lasting suppression of the inflammatory response in order to induce and maintain clinical remission. None the less, even in cases of successful treatment, subclinical inflammation of the intestinal wall may persist, contributing significantly to the risk of relapses.

Assessment of intestinal inflammation remains a difficult challenge. Currently, the most reliable method requires endoscopy with biopsy sampling, which is an invasive diagnostic tool; furthermore, in the case of Crohn's disease (CD), the site of the lesion cannot always be reached by endoscopy. The most widely used laboratory parameters of inflammation, such as the erythrocyte sedimentation rate (ESR) and $\mathrm{C}$ reactive protein (CRP), are not sufficiently specific or sensitive. Clinical indices of disease activity, such as the Crohn's disease activity index (CDAI), the ulcerative colitis activity index (UCAI), and the Harvey-Bradshaw activity index reflect the patient's well being and quality of life rather than the degree of mucosal inflammation..$^{2-5}$

Faecal calprotectin, an important granulocyte cytosolic protein, is closely correlated with faecal excretion of ${ }^{111}$ indium labelled leucocytes, deemed to be the gold standard for measuring intestinal inflammation. ${ }^{67}$ Assessment of faecal calprotectin levels has been proposed as a non-invasive test for the direct evaluation of intestinal inflammation in patients with IBD. ${ }^{8-10}$ Recently Tibble et al suggested that a high faecal calprotectin concentration may identify those IBD patients in remission who are at risk of early relapse, with no difference between ulcerative colitis (UC) and CD. ${ }^{11}$ On the other hand, a number of studies have shown that the predictive value of residual inflammation after drug induced clinical remission for relapses may be different in UC and CD. ${ }^{12}$
The aim of this study was to examine the role of intestinal inflammation in relapsing IBD using the surrogate marker of faecal calprotectin and to determine whether this marker has a different predictive value in UC and CD.

\section{MATERIALS AND METHODS}

\section{Patients}

We followed 79 consecutive IBD outpatients (38 with CD and 41 with UC) diagnosed on the basis of standard clinical, endoscopic, radiological, and histological criteria. All patients had been in clinical remission for 1-12 months (mean 5). Remission was determined by a disease activity assessment based on the $\mathrm{CDAI}^{13}$ for patients with $\mathrm{CD}$ and $\mathrm{UCAI}^{14}$ for patients with UC. Clinical features of the two patient groups are shown in table 1.

Patients who had experienced a clinical relapse within the last month or who were suffering from chronic active disease requiring treatment with steroids were excluded. None of the study subjects had taken non-steroidal anti-inflammatory drugs and/or antibiotics during the three months preceding their enrolment. Further exclusion criteria included: concomitant serious illnesses, pregnancy, or alcohol abuse. All patients were followed for 12 months, with clinical evaluation performed every three months or whenever a relapse occurred, including evaluation of CDAI or UCAI and routine blood tests. Clinical relapse was defined as the occurrence or worsening of symptoms, accompanied by an increase in the CDAI score to $>150$ or in the UCAI score to $>4$, sufficient to require a change in therapy (addition of steroids, immunosuppressors, surgery, etc). Each patient was invited to provide

\footnotetext{
Abbreviations: CRP, $C$ reactive protein; $C D$, Crohn's disease; CDAl, Crohn's disease activity index; ESR, erythrocyte sedimentation rate; IBD, inflammatory bowel disease; NPV, negative predictive value; PPV, positive predictive value; ROC, receiver operating characteristic; UC, ulcerative colitis; UCAl, ulcerative colitis activity index
} 
Table 1 Characteristics of Crohn's disease (CD) and ulcerative colitis (UC) patients at the beginning of the study

\begin{tabular}{|c|c|c|}
\hline & $C D$ & UC \\
\hline $\begin{array}{l}\text { Clinical activity indices (CDAl, UCAI)* } \\
\text { Age at onset }(y)^{*}\end{array}$ & $\begin{array}{l}84.6(55.3) \\
35.7(11.6)\end{array}$ & $\begin{array}{c}0.9(1.3) \\
41.2(12.7)\end{array}$ \\
\hline $\begin{array}{l}\text { Previous quiescent phase (months) }{ }^{*} \\
\text { Calprotectin }(\mu \mathrm{g} / \mathrm{g})\end{array}$ & $5.0(4.3)$ & $4.8(4.1)$ \\
\hline $\begin{array}{l}\leq 150 \\
>150\end{array}$ & $\begin{array}{l}12(31.6 \%) \\
26(68.4 \%)\end{array}$ & $\begin{array}{l}20(48.8 \%) \\
21(51.2 \%)\end{array}$ \\
\hline \multicolumn{3}{|l|}{ Sext } \\
\hline $\mathrm{F}$ & 22 (57.9\%) & 12 (29.3\%) \\
\hline M & $16(42.1 \%)$ & $29(70.7 \%)$ \\
\hline \multicolumn{3}{|l|}{ Smoking $†$} \\
\hline Ex & $3(7.9 \%)$ & 15 (36.6\%) \\
\hline No & $27(71.0 \%)$ & $22(53.7 \%)$ \\
\hline Yes & $8(21.0 \%)$ & $4(9.8 \%)$ \\
\hline \multicolumn{3}{|l|}{ Extent } \\
\hline Ileitis & 27 (71.0\%) & \\
\hline Ileocolitis & 5 (13.2\%) & \\
\hline Colitis & $6(15.8 \%)$ & \\
\hline $\begin{array}{l}\text { Proctosigmoiditis } \\
\text { Left sided colitis }\end{array}$ & & $\begin{array}{r}28(68.3 \%) \\
6(14.6 \%)\end{array}$ \\
\hline Pancolitis & & $7(17.1 \%)$ \\
\hline \multicolumn{3}{|l|}{ Therapy } \\
\hline Azathioprine & $2(5.3 \%)$ & $2(4.9 \%)$ \\
\hline Mesalazine & $32(84.2 \%)$ & $39(95.1 \%)$ \\
\hline No therapy & $4(10.5 \%)$ & $0(0 \%)$ \\
\hline \multicolumn{3}{|l|}{ Surgery } \\
\hline No & 35 (92.1\%) & 41 (100\%) \\
\hline Yes & $3(7.9 \%)$ & $0(0 \%)$ \\
\hline \multicolumn{3}{|c|}{$\begin{array}{l}\text { *Mean (SD) for continuous variables. NS by Wilcoxon rank sum test } \\
\text { †Exact text p value }<0.05 \text {. } \\
\text { CDAl, Crohn's disease activity index; UCAl, ulcerative colitis activity } \\
\text { index. }\end{array}$} \\
\hline
\end{tabular}

a single stool sample collected within 12 hours from delivery using a disposable plastic container.

All patients gave written informed consent before enrolment in the study.

\section{Laboratory parameters}

ESR (first hour) and CRP were assessed by standard methods (normal value ESR $<12 \mathrm{~mm} / \mathrm{h}$; normal value CRP $<5 \mathrm{mg} / \mathrm{l}$ ).

\section{Faecal calprotectin measurement}

Faecal calprotectin was measured on frozen $\left(-20^{\circ} \mathrm{C}\right)$ stool specimens using a commercially available quantitative enzyme linked immunoassay (Calprest; Eurospital, Trieste, Italy), as previously described. ${ }^{9}$

\section{Statistical analysis}

The series of 79 IBD patients was divided into two groups based on diagnosis: 38 with CD and 41 with UC. Patient characteristics were compared between the two groups using the Wilcoxon rank sum test for continuous variables and the exact test for categorical variables.

A dichotomous variable was assigned to each patient-that is, a value of 1 if the calprotectin level was $>150 \mu \mathrm{g} / \mathrm{g}$ and a value of 0 if calprotectin was $\leqslant 150 \mu \mathrm{g} / \mathrm{g}$. The cut off level of
$150 \mu \mathrm{g} / \mathrm{g}$ represented the point at which the area under the receiver operating characteristic (ROC) curve for predicting the relapse rate in both CD and UC patients was maximal.

Incidence rates were obtained for the UC and CD groups. In addition, each group was subdivided into patients with calprotectin levels above and below $150 \mu \mathrm{g} / \mathrm{g}$, Kaplan-Meier curves were obtained, and differences were tested using Mantel-Henzel log rank tests.

Univariate analysis was performed to determine the hazard ratios associated with each of the demographic and clinical parameters: sex, age at disease onset, previous quiescent phase, clinical index at the beginning of the study, smoking habits, extent of disease, medical therapy, and previous surgery.

Multivariate models were also constructed for the two patient groups as follows: all of the variables that in the univariate analysis showed an association with time to relapse were entered into multiple proportional hazard (Cox) regression models. Variables were then dropped from the model if they appeared to be non-significant by the Wald test ( $\mathrm{p}$ value less than $10 \%$ ). As each variable was eliminated, the coefficient associated with the dichotomous variable for calprotectin above or below $150 \mu \mathrm{g} / \mathrm{g}$ was checked. If its estimate changed by more than $10 \%$, the dropped variable was reintroduced into the model as a potential confounder. The dichotomous variable for calprotectin above/below $150 \mu \mathrm{g} / \mathrm{g}$ was always retained in the models. Pairwise interactions were also tested, and were not introduced because they were never found to be significant. All $\mathrm{p}$ values reported for the univariate and multivariate models were based on likelihood ratio tests.

\section{RESULTS}

The 79 patients were followed for up to one year. Table 2 shows data on the disease course for the two patient groups, which consisted of a similar number of patients, yielding a roughly equivalent number of person months. The incidence of relapses was slightly higher among UC patients, although the difference was not significant.

\section{Laboratory parameters}

In the CD group, median baseline ESR and CRP values were $15 \mathrm{~mm} / \mathrm{h}$ (95\% confidence interval (CI) 5.2-24.8) and $6 \mathrm{mg} / \mathrm{l}$ (95\% CI 2.5-9.5), respectively, in non-relapsing patients and $20 \mathrm{~mm} / \mathrm{h}$ (95\% CI 13.1-26.9) and $8 \mathrm{mg} / \mathrm{l}$ (95\% CI 5.6-10.4) in patients who relapsed during the follow up period. This difference was not statistically significant $(p=0.077$ for ESR and $\mathrm{p}=0.373$ for CRP).

Similarly, in UC patients, neither ESR nor CRP differed significantly between the relapsing and non-relapsing groups $(p=0.056$ for ESR and $p=0.45$ for CRP $)$; in particular, baseline ESR and CRP values were $11 \mathrm{~mm} / \mathrm{h}$ (95\% CI $8.8-$ $13.2)$ and $4.5 \mathrm{mg} / \mathrm{l}(95 \%$ CI $3.7-5.3)$ in the non-relapsing group and $15 \mathrm{~mm} / \mathrm{h}$ (95\% CI 10.9-19.1) and $5 \mathrm{mg} / \mathrm{l}$ (95\% CI 0.9-9.1) in the relapsing group, respectively.

ROC curves for ESR and CRP did not identify any differences between the relapse and non-relapse groups for both CD and UC. Because of the lack of significance for the

Table 2 Disease course in 79 patients with inflammatory bowel disease (IBD) (38 with ulcerative colitis (UC) and 41 with Crohn's disease (CD)) studied for a period of 12 months

\begin{tabular}{llllll}
\hline & $\mathbf{n}$ & Relapses & $\begin{array}{l}\text { Person } \\
\text { months }\end{array}$ & $\begin{array}{l}\text { Incidence } \\
\text { rate }\end{array}$ & $\begin{array}{l}\text { Mean follow up } \\
\text { (months) }\end{array}$ \\
\hline CD & 38 & 15 & 380 & 0.039 & 10.00 \\
UC & 41 & 19 & 393 & 0.048 & 9.59 \\
Total & 79 & 34 & 773 & 0.044 & 9.78 \\
\hline
\end{tabular}




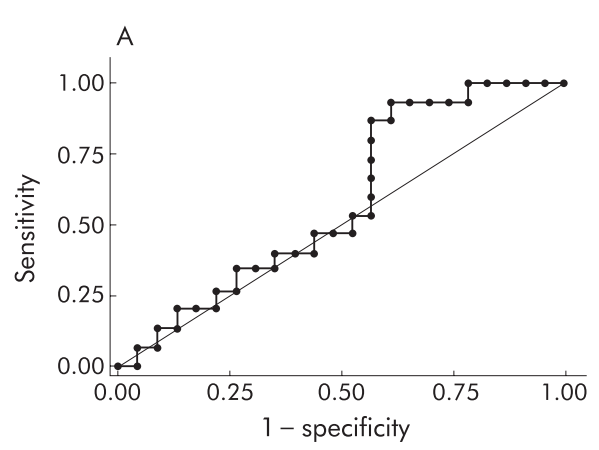

B

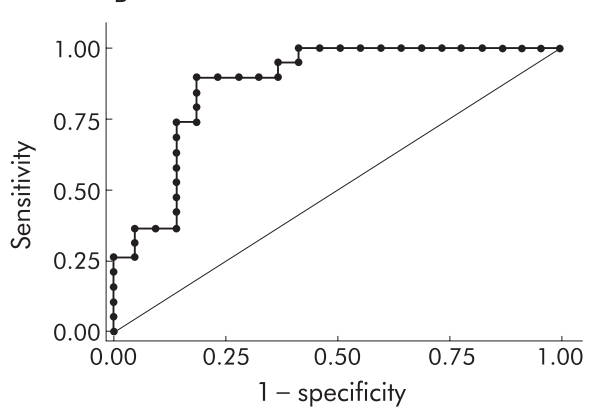

Figure 1 (A). Receiver operating characteristic (ROC) curve for faecal calprotectin in predicting the relapse rate in Crohn's disease. The area under the curve was 0.58 (95\% confidence interval (CI) $\mathrm{Cl} 0.40-0.77$ ). (B). ROC curve for faecal calprotectin in predicting the relapse rate in ulcerative colitis. The area under the curve was $0.87(95 \% \mathrm{Cl} 0.77-$ 0.98).

ROC curves, Kaplan-Meier plots of time to relapse were constructed using normal ranges as cut off values. A significant difference was found only for ESR in CD patients $(\mathrm{p}=0.022)$.

\section{Faecal calprotectin values}

Median faecal calprotectin concentration was $220.3 \mu \mathrm{g} / \mathrm{g}$ (95\% CI 92.2-348.4) in CD patients and $150.7 \mu \mathrm{g} / \mathrm{g}$ (95\% CI 70-231.4) in UC patients. Median calprotectin value in those CD patients who relapsed during follow up was $220.1 \mu \mathrm{g} / \mathrm{g}$ (95\% CI 21.7-418.5) compared with $220.5 \mu \mathrm{g} / \mathrm{g}$ (95\% CI 53$388)$ in non-relapsing patients $(p=0.395)$. Median calprotectin values in relapsing and non-relapsing UC patients were $220.6 \mu \mathrm{g} / \mathrm{g}$ (95\% CI 86-355.2) and $67 \mu \mathrm{g} / \mathrm{g}$ (95\% CI 15-119), respectively $(p<0.0001)$. No statistically significant difference in faecal calprotectin concentration was found among those who relapsed before six months and those who relapsed after six months in either patient group $(p=0.792$ for CD and $\mathrm{p}=0.422$ for UC). ROC curves for faecal calprotectin as a predictor of relapse in IBD are shown in fig $1 \mathrm{~A}$ and $1 \mathrm{~B}$. A statistically significant difference between $\mathrm{CD}$ and UC was found $(\mathrm{p}<0.0001)$.

A faecal calprotectin concentration of $150 \mu \mathrm{g} / \mathrm{g}$ gave a sensitivity of $89 \%$, a specificity of $82 \%$, a positive predictive value (PPV) of $81 \%$, and a negative predictive value (NPV) of $90 \%$ in predicting relapse in UC patients; in the CD group, sensitivity, specificity, PPV, and NPV were $87 \%, 43 \%, 50 \%$, and $83 \%$, respectively.

Figure 2 (A, B) shows Kaplan-Meier time to relapse survivor curves according to patients' faecal calprotectin levels by patient group. A calprotectin level greater than $150 \mu \mathrm{g} / \mathrm{g}$ was an important predictor of relapse for both UC $(p<0.0001)$ and CD $(p<0.05)$, although it was far stronger for UC. Among those patients with a calprotectin level greater than $150 \mu \mathrm{g} / \mathrm{g}$, half of the CD patients and more than $80 \%$ of
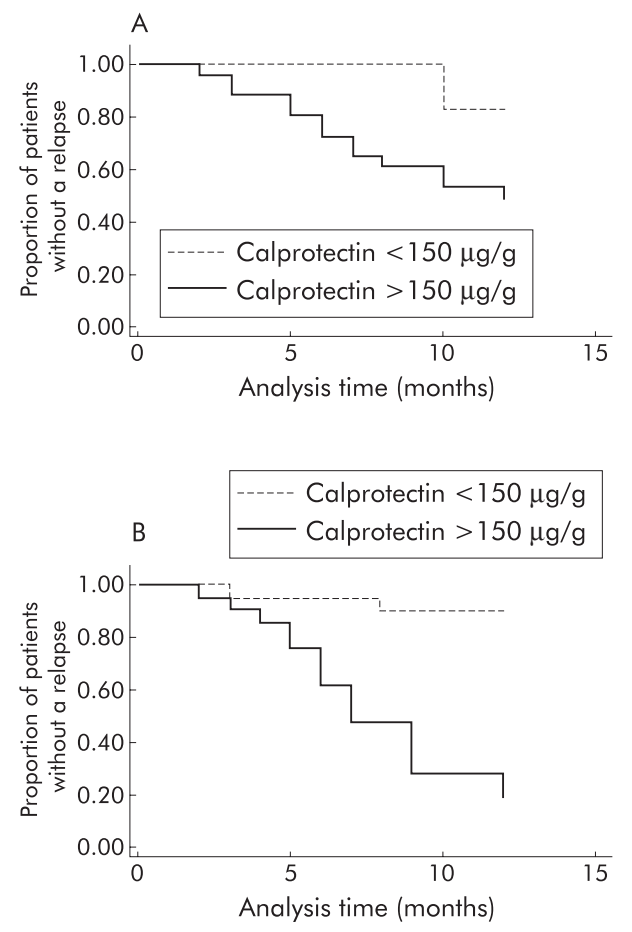

Figure 2 (A) Kaplan-Meier survivor curves for Crohn's disease patients, with values for calprotectin above and below $150 \mu \mathrm{g} / \mathrm{g}$. Log rank test for equality of survivor functions, $p$ value $=0.0432$. (B) KaplanMeier survivor curves for ulcerative colitis patients with values of calprotectin above and below $150 \mu \mathrm{g} / \mathrm{g}$. Log rank test for equality of survivor functions, $p$ value $=0.0000$.

the UC patients had relapsed by the end of the study $(\mathrm{p}=0.036)$.

Hazard ratios and 95\% CI associated with the dichotomous and continuous variables are presented in table 3 .

As shown in fig 2, those patients with higher levels of calprotectin were at higher risk of relapse; this risk was fourfold greater in CD and 12-fold greater in UC patients. Males and non-smokers were at lower risk in both diagnostic groups. Compared with smokers and non-smokers, ex smokers comprised patients at highest risk in both the CD and UC groups. Age and time to remission did not appear to influence the risk of relapse in the sampled patients. Estimated coefficients and 95\% CI of the multivariate Cox (proportional hazard) regression models are reported in table 4 for the two patient groups. As very few CD patients and no UC patient underwent surgery, this variable was not included in the multivariate analysis. Similarly, we did not include a variable for therapy because most patients were on the same treatment (mesalazine).

In both models three variables appeared to be significant predictors of the risk of relapse: high levels of calprotectin, CDAI or UCAI score, and smoking habits. Among these, calprotectin level was by far the most important, especially among UC patients. After adjusting for the remaining variables, high calprotectin values showed a twofold and 14-fold increase in the risk of relapse in CD and UC patients, respectively.

Cox regression models exploring possible interactions among ESR, CRP, and calprotectin did not show any additional predictive role for ESR and CRP if combined with calprotectin.

\section{DISCUSSION}

Our 12 month follow up study demonstrated that in patients with quiescent IBD, especially UC, faecal calprotectin 
Table 3 Univariate analysis of the hazard ratios (HR) and $95 \%$ confidence interval (CI) associated with the patient characteristics in the two groups

\begin{tabular}{|c|c|c|c|}
\hline & HR & $95 \% \mathrm{Cl}$ & LRT $p$ value \\
\hline \multicolumn{4}{|l|}{ CD patients } \\
\hline Calprotectin $(\mu \mathrm{g} / \mathrm{g})$ & & & 0.068 \\
\hline$\leqslant 150$ & 1 & - & \\
\hline$>150$ & 4.01 & {$[0.90-17.82]$} & \\
\hline Sex & & & 0.733 \\
\hline $\mathrm{F}$ & 1 & - & \\
\hline M & 0.84 & {$[0.30-2.35]$} & \\
\hline Smoking & & & 0.126 \\
\hline Ex & 1 & - & \\
\hline No & 0.28 & [0.06-1.32] & \\
\hline Yes & 0.76 & {$[0.15-3.96]$} & \\
\hline Extent & & & 0.122 \\
\hline Colitis & 1 & - & \\
\hline Mleitis & 0.26 & [0.79-0.89] & \\
\hline Ileocolitis & 0.52 & {$[0.12-2.36]$} & \\
\hline CDAl & 1.01 & [1.00-1.02] & 0.027 \\
\hline Age at onset (y) & 1.00 & {$[0.96-1.05]$} & 0.995 \\
\hline Previous quiescent phase (months) & 0.92 & {$[0.81-1.06]$} & 0.228 \\
\hline \multicolumn{4}{|l|}{ UC patients } \\
\hline Calprotectin $(\mu \mathrm{g} / \mathrm{g})$ & & & 0.000 \\
\hline$\leqslant 150$ & 1 & - & \\
\hline$>150$ & 12.82 & {$[2.93-56.05]$} & \\
\hline Sex & & & 0.788 \\
\hline $\mathrm{F}$ & 1 & - & \\
\hline M & 0.87 & {$[0.33-2.30]$} & \\
\hline Smoking & & & 0.411 \\
\hline Ex & 1 & - & \\
\hline No & 0.54 & {$[0.21-1.40]$} & \\
\hline Yes & 0.97 & {$[0.21-4.52]$} & \\
\hline Extent & & & 0.550 \\
\hline Pancolitis & 1 & - & \\
\hline Left sided colitis & 0.63 & {$[0.15-2.64]$} & \\
\hline Proctosigmoiditis & 0.54 & {$[0.18-1.56]$} & \\
\hline UCAI & 1.21 & {$[0.90-1.64]$} & 0.224 \\
\hline Age at onset (y) & 0.99 & [0.95-1.02] & 0.464 \\
\hline Previous quiescent phase (months) & 0.96 & [0.85-1.08] & 0.464 \\
\hline
\end{tabular}

concentration was a strong predictor of clinical relapse. The chosen cut off level of $150 \mu \mathrm{g} / \mathrm{g}$ was three times the upper limit of normal and gave the highest combined sensitivity and specificity as a predictor of relapse in IBD overall, as well as in UC and CD separately. Laboratory parameters (ESR, CRP) did not prove to be useful predictors of clinical relapse in IBD as a whole. Using Kaplan-Meier plots of time to relapse, we found a significant difference only for ESR in CD patients; however, possible combinations for calprotectin, ESR, and CRP in Cox regression models did not improve the predictive value of calprotectin alone.

In this study, we found that among IBD patients in clinical remission with a high faecal calprotectin level $(>150 \mu \mathrm{g} / \mathrm{g})$, $50 \%$ of $\mathrm{CD}$ patients maintained remission during the follow

Table 4 Adjusted hazard ratios (HR) and 95\% confidence interval (CI) associated with different variables based on Cox regression models in Crohn's disease (CD) and ulcerative colitis (UC) patients

\begin{tabular}{|c|c|c|c|}
\hline & HR & $95 \% \mathrm{Cl}$ & LRT $p$ value \\
\hline \multicolumn{4}{|l|}{ CD patients } \\
\hline Calprotectin $(\mu \mathrm{g} / \mathrm{g})$ & & & 0.312 \\
\hline$\leqslant 150$ & 1 & - & \\
\hline$>150$ & 2.20 & [0.44-11.12] & \\
\hline Smoking & & & 0.309 \\
\hline Ex & 1 & - & \\
\hline No & 0.29 & [0.05-1.55] & \\
\hline Yes & 0.57 & {$[0.10-3.07]$} & \\
\hline CDAl & 1.01 & [1.00-1.02] & 0.045 \\
\hline \multicolumn{4}{|l|}{ UC patients } \\
\hline Calprotectin $(\mu \mathrm{g} / \mathrm{g})$ & & & 0.000 \\
\hline$\leqslant 150$ & 1 & - & \\
\hline$>150$ & 14.39 & [3.15-65.84] & \\
\hline Smoking & & & 0.600 \\
\hline Ex & 1 & - & \\
\hline No & 0.59 & {$[0.21-1.67]$} & \\
\hline Yes & 0.90 & {$[0.19-4.27]$} & \\
\hline UCAI & 0.85 & [0.57-1.25] & 0.388 \\
\hline
\end{tabular}

CD, Crohn's disease; CDAl, Crohn's disease activity index; LRT, likelihood ratio test; UC, ulcerative colitis; UCAI, ulcerative colitis activity index. 
up period compared with 19\% of those with UC. As Crohn's colitis seems to have a more aggressive course, we may speculate that in our consecutive $\mathrm{CD}$ patients the low percentage of colonic disease could partially explain this discrepancy.

Thus while in UC we observed a clearcut difference in calprotectin levels between relapsing and non-relapsing patients, in the $\mathrm{CD}$ group high faecal calprotectin values were not necessarily a predictor of relapse. Furthermore, on multivariate analysis we found that some parameters (CDAI at inclusion, smoking habits) acted as potential confounders in predicting clinical relapse in the $\mathrm{CD}$ group, where the hazard ratio dropped from 4 to 2.2 , while in UC this value increased from 12.8 to 14.4. Our data therefore only partially confirm the recent findings of Tibble et al in the only other study on this topic ${ }^{11}$; they reported that calprotectin was an equally reliable predictor of relapse in UC and CD. Although a longer follow up on a larger series of IBD patients is needed, our findings deserve some discussion.

In IBD, the faecal calprotectin concentration appears to be a reliable parameter of mucosal inflammation although a correlation has been demonstrated with endoscopic and histological grading of disease activity only in UC. ${ }^{8}$

In this context, the different sensitivity of calprotectin in predicting relapse in UC and CD could reflect differences in the inflammatory pattern of these two diseases after drug induced clinical remission. In UC, 70\% endoscopic and 50\% histological healing post treatment has been reported and the presence of an acute (but not chronic) inflammatory infiltrate seems to be positively correlated with the relapse rate. ${ }^{12}$ This is in contrast with CD features; as shown in a large French, multicentre, prospective study, steroid induced clinical remission is associated with complete endoscopic healing ("no lesions or only healed lesions") in only 13\% of cases. ${ }^{3}$ Therefore, most CD patients, although they may appear clinically well, still have endoscopic lesions and significant intestinal inflammation. In addition, once clinical remission was achieved with steroid treatment, no difference was found in the relapse rate during an 18 month follow up period between endoscopically healed CD patients and those with persistent mucosal lesions. ${ }^{15}$ This is consistent with our findings of high faecal calprotectin levels in CD (but not UC) patients who were in long term clinical remission. In most of the cross sectional studies conducted thus far, CD patients showed high faecal calprotectin levels; normal concentrations were found only in those who had undergone surgery and exhibited no endoscopic signs of recurrence. ${ }^{7}$ Interestingly, preliminary data from Roseth suggested that in CD patients treated with infliximab, faecal calprotectin levels normalise in parallel with endoscopic healing. ${ }^{16}$

Taken together, this evidence suggests that faecal calprotectin, which reflects the inflammatory status of the intestinal mucosa, is an even stronger predictor of relapse in UC than in $C D$, where intestinal inflammation is not always a harbinger of clinical symptoms. Conversely in UC, incomplete resolution of the inflammatory infiltrate during clinical remission seems to be responsible for eventual relapses.

It could be argued that in CD, evaluation of remissions and relapses are usually based on the CDAI value, which represents a subjective and indirect assessment of gut inflammatory activity because it includes certain variables and symptoms not directly correlated with active inflammation and expression of severity rather than activity of disease. Moreover Saverymuttu reported that $89 \%$ of CD patients in clinical remission $($ CDAI $<150)$ show greater faecal ${ }^{111}$ In granulocyte excretion than patients with irritable bowel syndrome, and concluded that CDAI underestimates gut inflammation. ${ }^{17}$
It is possible that stratification of patients on the basis of their disease pattern (inflammatory, stricturing, penetrating) could overcome some of these problems; although still speculative, it is reasonable to hypothesise that the inflammatory subgroup of $\mathrm{CD}$ ( $\mathrm{Bl}$ according to the Vienna classification) would have the best correlation with a direct marker of acute gut inflammation, such as calprotectin.

We conclude that the significant correlation between faecal calprotectin concentration and the relapse rate in UC makes the faecal calprotectin assay a potentially useful non-invasive tool for monitoring and adjustment of treatment. If these data are confirmed, we speculate that acute phase therapy could be tapered once the faecal calprotectin concentration drops below $150 \mu \mathrm{g} / \mathrm{g}$. Moreover, our results confirm that a subgroup of UC patients seems to be at high risk of developing colitis relapse; it should be highlighted that, as previously suggested by Riley and colleagues ${ }^{1}$ and subsequently by Tibble and Bjarnason, ${ }^{18}$ patients with UC in clinical remission should be stratified according to their level of intestinal inflammation when maintenance drug trials are planned.

\section{Authors' affiliations}

F Costa, M G Mumolo, L Ceccarelli, M Bellini, M R Romano, C Sterpi, A Ricchiuti, S Marchi, Department of Internal Medicine, Section of Gastroenterology, University of Pisa, Pisa, Italy

M Bottai, Arnold School of Public Health, University of South Carolina, Columbia SC, USA

Conflict of interest: None declared.

\section{REFERENCES}

1 Riley SA, Mani V, Goodman MJ, et al. Microscopic activity in ulcerative colitis: what does it mean? Gut 1991;32:174-8.

2 Crama-Bohbouth G, Pena AS, Biemond I, et al. Are activity indices helpful in assessing active intestinal inflammation in Crohn's disease? Gut 1989;30:1236-40.

3 Modigliani R, Mary JY, Simon JF, et al. Clinical, biological, and endoscopic picture of attacks of Crohn's disease. Gastroenterology 1990;98:811-18.

4 Cellier C, Sahmoud T, Froguel E, et al. Correlations between clinical activity, endoscopic severity, and biological parameters in colonic or ileocolonic Crohn's disease. A prospective multicentre study of 121 cases. Gut 1994;35:231-5.

5 Biancone L, De Nigris F, Del Vecchio Blanco G, et al. Review article: monitoring the activity of Crohn's disease. Aliment Pharmacol Ther 2002; 16(suppl 4):29-33.

6 Roseth AG, Schmidt PN, Fagerhol MK. Correlation between faecal excretion of indium-1 11 -labelled granulocytes and calprotectin, a granulocyte marke protein in patients with inflammatory bowel disease. Scand J Gastroenterol 1999;34:50-4.

7 Tibble JA, Teahon K, Thiodleifsson B, et al. A simple method for assessing intestinal inflammation in Crohn's disease. Gut 2000;47:506-13.

8 Roseth AG, Aadland E, Jahnsen J, et al. Assessment of disease activity in ulcerative colitis by faecal calprotectin, a novel granulocyte marker protein. Digestion 1997;58:176-80.

9 Costa F, Mumolo MG, Bellini M, et al. Role of faecal calprotectin as a noninvasive marker of intestinal inflammation. Dig Liver Dis 2003;35:642-7.

10 Limburg PJ, Ahlquist DA, Sandborn WJ, et al. Faecal calprotectin levels predict colorectal inflammation among patients with chronic diarrhea referred for colonoscopy. Am J Gastroenterol 2000;95:2831-7.

11 Tibble JA, Sigthorsson G, Bridger S, et al. Surrogate markers of intestinal inflammation are predictive of relapse in patients with inflammatory bowel disease. Gastroenterology 2000;119:15-22.

12 Modigliani R. Endoscopic management of inflammatory bowel disease. Am J Gastroenterol 1994;89(suppl 8):53-65.

13 Best WR, Becktel JM, Singleton JW. Re-derived value of the eight coefficients of the Crohn's disease activity index (CDAI). Gastroenterology 1979;77:843-6.

14 Rachmilewitz D. Coated mesalazine (5-aminosalicylic acid) versus sulphasalazine in the treatment of active ulcerative colitis: a randomised trial. BMJ 1989;298:82-6.

15 Landi B, N'Guyen Anh T, Cortot A, et al. Endoscopic monitoring of Crohn's disease treatment: a prospective, randomized clinical trial. Gastroenterology 1992; 102:1647-53

16 Roseth AG. Determination of faecal calprotectin, a novel marker of organic gastrointestinal disorders. Dig Liver Dis 2003;35:607-9.

17 Saverymuttu SH. Clinical remission in Crohn's disease-Assessment using faecal ${ }^{111}$ In granulocyte excretion. Digestion 1986;33:74-9.

18 Tibble JA, Bjarnason I. Non-invasive investigation of inflammatory bowel disease. World J Gastroenterol 2001;7:460-5. 